\title{
Predictive Factors for the Intention to Adopt a Mobile Blackboard Course Management System: The Case Study of University of Hai'l in Saudi Arabia
}

\author{
Ayman N. Alkhaldi" ${ }^{*}$ and Abdallah M. Abualkishik ${ }^{2}$ \\ 'Management Information Systems Department, University of Hai'l, Hai'l, Kingdom of Saudi Arabia, \\ Saudi Arabia; ayman_alkhaldi@hotmail.com \\ 2Sohar University, Oman; aabualkishik@soharuni.edu.om
}

\begin{abstract}
Objective: This study is to propose a model that investigates the predictive factors influencing the intention to adopt mobile blackboard. Methods and Analysis: Researchers used quantitative research method. A survey questionnaire with closed questions was also used. A cross-sectional survey was conducted for data collection. A random sample was stratified to target certain respondents (i.e., students at university of Hai'l in Saudi Arabia). The quantitative data were analyzed using SPSS 17.0. Findings: The factors of self-management of learning, social influence, perceived playfulness, previous experience, performance expectancy, and effort expectancy are positively effect on the behavioral intention to adopt mobile blackboard as expected, except for the cost factor. Although the users' previous experience has a negative moderating effect on the correlation for both effort expectancy and the intention to adopt the mobile blackboard system, while it didn't affect the relation between intentions to adopt mobile blackboard with performance expectancy factor. Novelty/Improvement: This study developed an innovative mobile learning model, and assured the validity of the learning model in this context. Researchers recommended employing the new conceptual model in different settings, technologies, and countries.
\end{abstract}

Keywords: Course Management System, Electronic Learning, Intention to Adopt, Learning Management System, Mobile Blackboard, Mobile Learning

\section{Introduction}

As smartphone usage continues to increase worldwide, it is expected that the global smartphone penetration will reach $60 \%$ in 2019 . Smartphone penetration is taking place in the Middle East as well. A statistical study conducted by ${ }^{1}$ stated that growth predictions show that by 2017 , Saudi Arabia was leading 4G markets in the Middle East, with more than 11 million subscriptions. In the Saudi Arabia, there is a presence of a large number of young people who accept the latest technology with great enthusiasm. The widespread acceptance of smartphones and developments in mobile internet technology are the country's main drivers of development. In Saudi Arabia, the Saudi government continues to invest in the development of telecommunications infrastructure, which supports many types of internet-enabled services. In Saudi Arabia, the mobility infrastructure and networks are in the developed phase ${ }^{2}$.

The developed telecommunications infrastructure along with the widespread mobile penetration, especially among young people (including university students), presents the opportunity of extensive implementation of modern mobile educational technologies such as a mobile blackboard ( $m$-blackboard). The daily usage of such tools by the younger generation would equip them to adopt shifting learning practice from traditional (i.e., face-to-face) learning to mobile learning (m-learning) ${ }^{3}$. That is, with the growing up of mobile smartphones penetration, $\mathrm{m}$-learning is expected to dominate the field of learning ${ }^{4}$. M-learning alludes to reachthe students at any time and place through the utilization of remote web

${ }^{*}$ Author for correspondence 
and mobile technology ${ }^{5}$. In educational institutions, the advantages of mobile penetration should be exploited through presenting a Learning Management System (LMS) services via mobile phones ${ }^{6}$. Unfortunately, although mobiles are widespread between students, their perception, familiarity, and willingness to use mobiles in learning is still limited and therefore should be studied, especially in various contexts and countries ${ }^{7}$.

Even with the evolution of the telecommunications infrastructure, m-learning is still in the implementation stage, and its theoretical foundations have not yet fully developed, especially in developing countries ${ }^{4}$. For example, the LMS has been successfully implemented in developed countries ${ }^{6} ;$ however, in developing countries it has generally failed, and its utilization is partial ${ }^{8}$. For example, in Saudi Arabia, many universities have implemented LMS for years, but its utilization is below the satisfactory level among students. Self-factors, organizational, technological, and self-efficacy are supposed to be the main challenges in such countries? This is because different contexts, users, and institutions face different challenges ${ }^{6}$. An evidence is provided by ${ }^{10}$, who assessed the recent situation of $\mathrm{m}$-services adoption in Saudi Arabia to provide a better understanding. They observed low adoption, and the reason for this is associated with user issues. These issues have been seldom surveyed for m-services in Saudi Arabia, and hence remain unknown. However, the implementation of m-blackboard can be successful only if students are engaged in using such a system. Attaining the adoption of the m-blackboard system by students is a serious challenge.

It is worth mentioning that there is an association amidst LMS utilization and students' performance in courses presented by the LMS. Therefore, educational institutions should take advantage of the mobile penetration by offering LMS services via mobile phones ${ }^{6}$. Unfortunately, according to the records of universities in the Saudi Arabia, the count of students who effectively utilizing $\mathrm{m}$-blackboard systems is tied contrasted to the total number of students. Since that, m-learning adoption should be investigated from the standpoint of students in higher education for effective m-learning applying in Saudi Arabia ${ }^{11}$. To this end, we conducted a case study of universities in the Saudi Arabia. Our aim was to response of two research questions. What are the predictive variables that influence users' intention to adopt m-blackboard in Saudi Arabia? How do users perceive such factors? To fill this lacuna, researchers developed a conceptual model that represents the predictive factors of the intention to adopt m-blackboard in Saudi Arabia.

\section{Background Incidents}

LMSs, such as Blackboard, are adopted by many educational institutions to improve learning. Blackboard platforms act as a communications bridge between instructors and students, providing both synchronous and asynchronous interactions, all can be via smartphones ${ }^{5}$. However, LMS faces different type of challenges and barriers that affect its usage. Despite the extensive purpose of m-blackboard in the learning environment, m-learning in higher education is until now in its infancy in the LMS ${ }^{12}$, and mobile learning management system (M-LMS) $)^{13}, \underline{14}$. Students communicate, learn, and live in innovation environment that is leading by latest technologies. Since universities need to have a competitive environment that convoy technology growth, many factors could impact the usage of m-learning in higher education context. The accessibility of mobile technology does not promise that it would be applied in an educational context. In the same manner, merely adopting latest technology does not promise its learning success. However, several academic organizations have endeavored to aid E-learning, whereas this study focused more on the use of M-LMS. Studies investigating cases, about entirety aspects of learning occur via a mobile device are limited ${ }^{13}$. Limited studies have been run to investigate factors impacting the adoption of M-LMS ${ }^{14}, 13$ have called for further researches to determine why students use M-LMS.

There are certain factors that play a role in user perception and should be considered for a better understanding of students' perceptions concerning the M-LMS. The literature on M-LMS reports fragmented findings; previous studies did not adopt a comprehensive view. For example, ${ }^{14}$ found latent relationships between M-LMS use and students' psychological characteristics (i.e., innovativeness, self-efficacy, perceived usefulness, and perceived ease of M-LMS use). This was supported by $^{9}$, who reviewed the literature on LMS adoption and reported that the factors of enjoyment and self-efficacy were frequently surveyed and their effects were proved.

Other studies have explored the influence of technological infrastructure on the use of M-LMS. $\frac{15}{-5}$ presented that $53 \%$ of the students were found M-LMS 
hard to understand, difficult to use, required much effort, and they do not know the ideal procedure to utilize the system using mobile phones ${ }^{16}$. This was supported by ${ }^{17}$, who studied related works on m-learning in higher education institutions. The core restrictions stated by the studies were associated with technological infrastructure issues, such as poor connection and lack of access to new mobile devices. That is, still many undergraduates outlined having adequate means to engage mobile devices for learning aims, yet, they are interested to adopt and use M-LMS applications, only if, M-LMS are made easy to access and use ${ }^{18}$. These studies proved that students' behavior and perceptions of M-LMS adoption might change depending on the technological infrastructure that possibly differs from one context to another.

The current study argues that the use of M-LMS is influenced by multi-dimensional characteristics of issues, as suggested by ${ }^{14}$. Therefore, we focused on the user perception and infrastructure issues comprehensively.

\section{Build Conceptual Model based Acceptance Theoretical Models}

Theoretical acceptance models are indeed diverse in features, and no acceptance theory is perfect. These acceptance models have constraints in inspect technology adoption and use. For example, the TAM is frequently applied to examine technology acceptance and primarily destined to be functional in the technology usage settings only. In the meantime, Unified Theory of Acceptance and Use of Technology (UTAUT2) is more powerful and exclusive and can explain approximately $70 \%$ of the disparity in the users' behavioral intention to apply a technology ${ }^{19}$. The UTAUT is a common acceptance theory that captures the dynamic factors of several acceptance theories ${ }^{20}$. The UTAUT is more comprehensive because the original UTAUT was developed based on combining eight acceptance theoretical theories by eliminating stuffing of some constructs to formulate a unified view of acceptance theories ${ }^{19}$. UTAUT is innovative compared to other acceptance theories. Its reliability and validity were proven through several studies in diverse contexts, such as $\mathrm{m}$-banking context, $\mathrm{m}$-government, and $\mathrm{m}$-learning. The UTAUT is found to be the most successfully employed and extended in the m-learning setting $\underline{21}$. Evidence of its validity to be employed in developing countries was provided, especially in Saudi Arabia ${ }^{22}$. UTAUT can be extended to include new external variables; it is capable of explaining higher education students' adoption of $\mathrm{m}$-learning ${ }^{7}$. Based on this, the applicability of UTAUT from different considerations and perspectives was proven through the literature.

In the field of m-learning endorsement, numerous factors have been reported by different studies as predictors of users' intention to adopt $t^{23}$ studied all UTAUT factors and other variables (i.e., perceived playfulness and self-management of learning). Their study ensured that performance expectancy, effort expectancy, social factors, facilitating conditions, perceived playfulness, and selfmanagement of learning are powerful determinants of intention to adopt m-learning. Furthermore, referring to the review of previous related work of m-learning models, most studies reported the significance of factors, such as self-management of learning, facilitating conditions, social influence, perceived playfulness, cost, performance expectancy, effort expectancy, and previous experience. Factors, namely facilitating conditions, social influence, performance expectancy, effort expectancy, and experience, are theorized in the original UTAUT, as stated by ${ }^{23}$, and they call for extending the UTAUT to include new variables for further investigation of m-learning adoption. In contrast, only a few theoretical-based studies were conducted to investigate the user's perceptions of M-LMS.

These studies investigated the adoption of m-learning in general, and did not focus on M-LMS in particular, which is different to m-learning because m-learning is more personal, where learning content is personalized for the individual learner. These promising findings call for more focus from the perspective of the authors of this study.

The factors, perceived ease of use and perceived usefulness, were surveyed by the literature of the current study, but not adapted to be explored. This study extended the UTAUT, which was developed by ${ }^{20}$. The best justification for when Venkatesh captured the essential elements from eight acceptance models to develop the UTAUT without any redundancy of similar factors is that the performance expectancy was driven from the perceived usefulness (TAM, TAM2, and IDT), and they captured the factor perceived ease-of-use from TAM and TAM2 to outline the effort expectancy ${ }^{24}$. In the study of $\frac{25}{5}$, performance expectancy represented various variables at different models as perceived usefulness from 
TAM, exterior motivation from motivational model, job fit from PC utilization model, relative advantages from innovation diffusion theory, and outcome expectations from social cognition theory. Ghalandari also defined effort expectancy as "the extent of convenience perceived for using the system". He mentioned that in other models, like TAM, effort expectancy was identical to the perceived ease of use. Regarding mobile self-efficacy, $\mathrm{In}^{26}$, mobile self-efficacy is defined as the capability of students to use mobile devices. The authors highlighted that self-efficacy is an important factor that needs to be investigated $\mathrm{d}^{27}$. also found that the learner's self-efficacy is increasing day by day, where the technology has become widespread. This could be reason that self-efficacy does not anymore appear to be promising the behavioral intention to use LMS. Also, $\frac{28}{}$ reported that self-efficacy doesn't have a positive influence on the perceived usefulness of LMS. Thus, perceived ease of use, perceived usefulness, and mobile self-efficacy factors will not be hypothesized in the conceptual model of the current study. Next sessions are the theoretical supports of the hypotheses in this study.

\subsection{Self-Management of Learning}

Self-management of learning is the level to involve in self-governed learning and is self-disciplined. As $\mathrm{m}$-learning systems can be run by using mobile devices, it is predicted that self-management of learning will significantly impact the desire to adopt such a system..$\underline{23}$ mentioned that many literatures have found a positive result of self-management of learning on the intention to adopt m-learning. In UTAUT, self-management of learning could describe high distinctions in the used behavior, particularly in m-learning, as reported by ${ }^{4}$. Upon that, researchers hypothesize that:

$\mathrm{H1}$ : Self-management of learning has a positive effect on the intention to adopt M-blackboard system in university of Hai'l in Saudi Arabia.

\subsection{Cost}

Cost is one of the main factors impacting students in using technology. It considers as one of the eight most routinely investigated factors in exploring m-learning adoption ${ }^{4}$. $\mathrm{In}^{29}$ proposed found that perceived financial cost crucially impact person intention to utilize smartphones for education. Meanwhile, $\frac{19}{}$ introduced three new constructs in the UTAUT 2 . Price was considered as the most significant factor in determining the user's preference to utilize a particular technology. M-learning is cost-saving and cost-effective. For example, when learners use their own mobile devices, this could remove technological barriers to accessing learning resources ${ }^{4}$. Therefore, the cost factor is anticipated to encourage students' intention to adopt the m-blackboard learning system, as hypothesized:

H2: Cost has a negative effect on the intention to adopt m-blackboard system in university of Hai'l in Saudi Arabia.

\subsection{Social Influence}

Social influence refers to "the degree to which an individual perceives that others believe he or she should use the new system" $\stackrel{30}{ }$. In the adoption of mobile systems, social influence appears to exert pressure on individuals to adopt.

Social pressure (or social influence) in technology adoption has been extensively addressed in the literature. For instance,,$\frac{31}{1}$ confirmed that a limitation of the TAM was that it did not consider the social influence factor along with the two key determinants, namely, perceived usefulness and perceived ease of use. Subsequently, this resulted in including social influence in the original UTAUT, developed by ${ }^{20}$. All previous studies on $\mathrm{m}$-learning such as those by $4,18,29, \underline{22}-\underline{39}, \underline{29}$ have reported the significance of the social influence predictor in m-learning through the UTAUT. Therefore, grounded in the UTAUT and supported by related studies, the following hypothesis is presented:

H3: Social influence has a positive effect on the intention to adopt M-blackboard system in University of Hail in Saudi Arabia.

\subsection{Perceived Playfulness}

${ }^{26}$ outlined perceived playfulness as "the degree to which a person believes that interaction with the mobile system is pleasant". According to ${ }^{23}$, individuals will gain intrinsic motivation because of their perception of playfulness, when they become completely engaged in a technology. The pleasure of using the mobile system will tend to believe that the mobile system is not difficult to use and "try to use it". ${ }^{4}$ employed the UTAUT along with perceived playfulness and reported that it explained high variations in the usage behavior of m-learning. They recommended considering the perceived playfulness 
factor in future m-learning research. Therefore, the following is hypothesized:

H4: Perceived playfulness has a positive effect on the intention to adopt m-blackboard system in university of Hai'l in Saudi Arabia.

\subsection{Performance Expectancy}

Performance expectancy is "the degree to which an individual believes that using the system will help him or her to attain gains in job performance" 30 . In the m-learning subject, the usage of performance expectancy factor proposes that individual understand the m-learning system to be valuable where it allows them to fulfill learning schemes more functionally, readily and resiliently. The performance expectancy was described as the most powerful variable of intention to adopt m-learning by a research affecting 330 respondents in Taiwan. Alike findings were found by other literature such a $\mathrm{s}^{2 \underline{3}}$ in the context of Malaysia, $, 4,18,21, \underline{33}, \underline{35}$. As no project has examined this linkage in Saudi Arabia, this study hypothesizes that:

H5a: Performance expectancy has a positive effect on the intention to adopt $\mathrm{m}$-blackboard system in university of Hail in Saudi Arabia.

\subsection{Effort Expectancy}

Effort expectancy is defined as "the degree of ease associated with the use of the system" $\underline{30}$. In m-learning, effort expectancy is the users' anticipation of utilizing m-learning with fewer prospects. The simpler the m-learning system is grasped to be by individuals, the better is the intention to adopt it. Paradoxical results were found by researchers in several countries, concerning the impact of effort expectancy on the intention to adopt m-learning ${ }^{23}$. However, the majority of these studies, such as, $\underline{33}, \underline{18}, \underline{21}, \underline{36}, \underline{35}, \underline{4}$ reported a positive impact of effort expectancy on the intention to adopt m-learning. A study run by 37 found that effort expectancy was a positive predictor of existing usage between undergraduate in Jordanian educational institution. Thus, this study hypothesizes that:

H6a: Effort expectancy has a negative effect on the intention to adopt $\mathrm{m}$-blackboard system in university of Hail in Saudi Arabia.

\subsection{Mobile Experience}

Users' mobile experience was considered as a key factor in technology adoption. For example, $\frac{38}{-}$ updated the TAM model to include previous experience as an external factor. Their results showed that the non-experienced user showed higher intention toward using LMS. 39Also found a significant positive correlation amidst mobile period use, mobile recurrence use, mobile experience, and respondents' perspectives in the direction of applying mobile technology.

The vital role of users' experience in m-learning adoption was confirmed by ${ }^{32}$, who asserted that individuals who have experience in using a modern technology are exceedingly bettered to intend to use it than those who do not. This study responded to the suggestion by ${ }^{4}$ that users' previous experience should be integrated through the UTAUT for investigating m-learning systems. To the best of our knowledge, no study has yet investigated the users' mobile experience in m-learning adoption. According to the mentioned evidences, this study proposes that:

H7: Mobile experience has a positive effect on the intention to adopt M-blackboard system in university of Hail in Saudi Arabia.

The level of users' mobile technology experience might decrease their perception of the effort required to use m-learning. In addition, users' perceptions inconstant during the time as they gain more experience. In ${ }^{40}$ proposed reported that students with more prior mobile device experience perceived m-learning as more useful (i.e., more performance) and easier to use (i.e., less effort). These findings are consistent with those of $\underline{20}$, who developed the original UTAUT. They found that effort expectancy was more significant for individuals with less experience, and it affected the behavioral intention for IT usage more at an early stage of experience. Further, ${ }^{41}$ asserted the requirement to find insomuch as or not there is a discrepancy among mobile users and nonmobile users in m-learning adoption. Thus, this study hypothesizes the following:

H6b: Mobile experience has a positive moderating effect on the relationship between performance expectancy and the intention to adopt the M-blackboard system in university of Hail in Saudi Arabia.

H7b: Mobile experience has a negative moderating effect on the relationship between effort expectancy and the intention to adopt the M-blackboard system in university of Hail in Saudi Arabia. 


\subsection{Facilitating Conditions}

Facilitating conditions refer to "the degree to which an individual believes that an organizational and technical infrastructure exists to support the use of the system" 30 . Adoption of any technology (especially new technology) is extremely related to the associated environment and infrastructure readiness. Through m-learning implementation, internet speed, resources, and personnel support are consider as facilitating conditions $s^{32}$. Many studies, such as, $, \underline{22}, \underline{18}, 23,36,34, \underline{35}, \underline{36}, \underline{37}, \underline{39}, 29, \underline{4}$ found that the facilitating conditions represent a significant factor for m-learning adoption. However, this study argues that facilitating conditions differ from one educational organization to another. Therefore, this study postulates that:

H8: The facilitating conditions have a positive effect on the intention to adopt m-blackboard system in university of Hail in Saudi Arabia.

Considering all the above hypotheses, a concluded model of M-Blackboard adoption for the students was proposed. The intention to adopt $\mathrm{m}$-learning is a subjective probability that the person will interact in a specific operational behavior. In order to investigate the factors those are affecting the intention to adopt M-blackboard by students. Researchers built the proposed conceptual model as shown in Figure 1 based on the study sample.

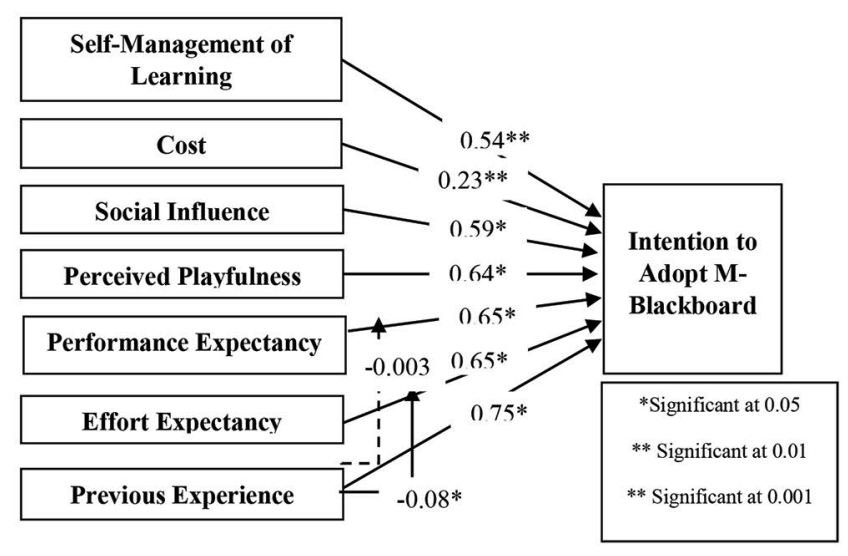

Figure 1. Proposed model.

\section{Methodology}

\subsection{Data Collection and Samples}

This study used quantitative research method. A survey questionnaire with closed questions was used to facilitate the respondents' understanding in answering the questions. A cross-sectional survey was conducted for data collection. A random sample was stratified to target certain respondents (i.e., students at university of Hail in Saudi Arabia). The questionnaire was administered personally by the author and an assistant research student. Online questionnaire distribution was conducted via WhatsApp to reach a greater number of students. As a result, 212 usable responses were received, and the overall response rate was $26.8 \%$.

\subsection{Measurement}

The survey questionnaire consisted of two main sections. The first section asks for respondent demographic information. The second section was associated with the research model variables. The variables were measured using a five-point Likert-type scale ( 1 = strongly disagree and $5=$ strongly agree).

The questionnaire questions were adapted from several studies. The adapted questions were modified to be compatible with the current study. The model presented in Figure 2 consists of a dependent variable (intention to adopt m-blackboard) and four independent variables adopted from UTAUT: intention to adopt m-blackboard by students, performance expectancy, effort expectancy, social influence, and facilitating conditions $s^{20}$. These variables were measured using 4,3 , 4, 3, 4 items, respectively. Other variables include selfmanagement learning and perceived playfulness, which were measured using 3 items each; these were adapted from the studies by $23, \underline{22}, \underline{43}$. Cost was measured using 4 items, which were adapted from $\underline{29}, \underline{19}, \underline{44}$, and previous

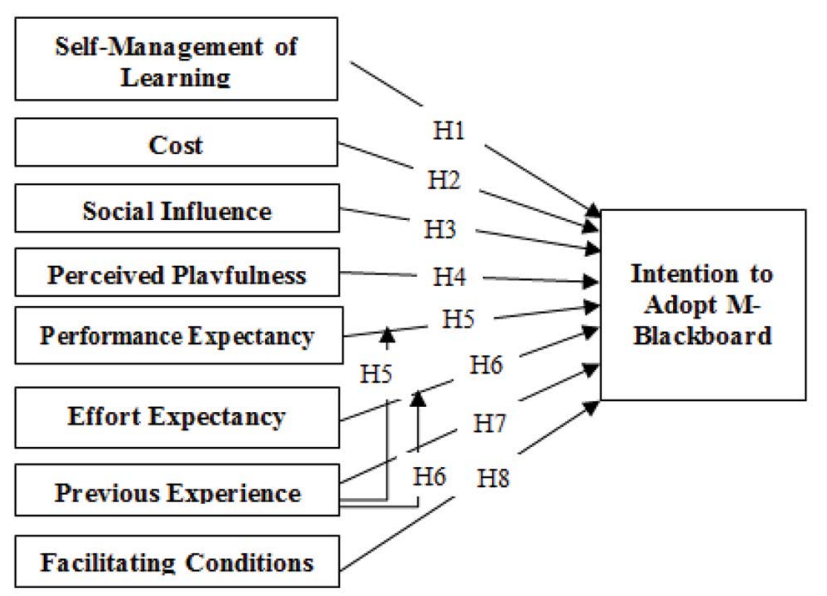

Figure 2. Developed model.F 
experience was measured using 3 items, which were adapted from $38, \underline{39}, \underline{45}-\underline{48}$.

The questionnaire was primarily formulated in English; however, it was necessary to translate it into Arabic, as this study was conducted in Saudi Arabia, where Arabic is the official language. The questionnaire questions are shown in Table 1.

\subsection{Data Analysis}

The quantitative data were inspected using SPSS 17.0. A descriptive analysis was employed to present the description and mean score value of the variables. Further, a Cronbach's alpha was calculated to test the internal consistency of the variables. A Pearson's correlation was utilized to determine the relationships among the

Table 1. Questionnaire questions (measurement items)

\begin{tabular}{|c|c|c|}
\hline Construct & Code & Measurement item description \\
\hline \multirow{3}{*}{$\begin{array}{l}\text { Self-Management of } \\
\text { Learning } \\
(\mathrm{SML})\end{array}$} & SML1 & I have the ability to learn by myself \\
\hline & SML2 & I can impose self-control on my learning \\
\hline & SML3 & I can achieve my learning goals by accessing blackboard using my smart phone \\
\hline \multirow{4}{*}{$\begin{array}{l}\text { Facilitating Conditions } \\
\text { (FC) }\end{array}$} & FC1 & I have the resources necessary to use blackboard mobile \\
\hline & FC2 & I had the knowledge necessary to use blackboard mobile \\
\hline & FC3 & Internet speed is appropriate for blackboard mobile \\
\hline & FC4 & A specific person was available for assistance with blackboard difficulties or quires \\
\hline \multirow[t]{3}{*}{ Social Influence (SI) } & SI1 & People who influence my behavior will think that I should use blackboard mobile \\
\hline & SI2 & People who are important for me will think that I should use blackboard mobile \\
\hline & SI3 & In general, the university support the use of blackboard mobile \\
\hline \multirow{3}{*}{$\begin{array}{l}\text { Perceived Playfulness } \\
(\mathrm{PP})\end{array}$} & PP1 & When using blackboard mobile I will not realize the time elapsed \\
\hline & PP2 & When using blackboard mobile, I will not forget the work I must do \\
\hline & PP3 & Using blackboard mobile will give enjoyment to me for my learning \\
\hline \multirow[t]{4}{*}{ Cost $(\mathrm{C})$} & $\mathrm{C} 1$ & The cost of using mobile blackboard is higher than using other Internet channels \\
\hline & $\mathrm{C} 2$ & The wireless link fee is expensive when using mobile blackboard \\
\hline & $\mathrm{C} 3$ & The mobile device setup to using mobile blackboard charges me lot of money \\
\hline & $\mathrm{C} 4$ & Using mobile blackboard services is cost burden to me \\
\hline \multirow{3}{*}{$\begin{array}{l}\text { Performance Expectancy } \\
(\mathrm{PE})\end{array}$} & PE1 & Using mobile blackboard would improve my performance \\
\hline & PE2 & Using mobile blackboard would save my time \\
\hline & PE3 & I would use mobile blackboard anywhere \\
\hline \multirow[t]{4}{*}{ Effort Expectancy (EE) } & EE1 & Learning to use mobile blackboard is easy for me \\
\hline & EE2 & Becoming skillful at using mobile blackboard is easy for me \\
\hline & EE3 & Interaction with mobile blackboard is easy for me \\
\hline & EE4 & I would find mobile blackboard is easy to use \\
\hline \multirow{3}{*}{$\begin{array}{l}\text { Previous Experience } \\
(\mathrm{PEX})\end{array}$} & PEX1 & My knowledge in mobile phone applications enable me to use blackboard system \\
\hline & PEX2 & Using other online system was beneficial for me \\
\hline & PEX3 & $\begin{array}{l}\text { My previous experience on online application through mobile encourage me to use } \\
\text { blackboard }\end{array}$ \\
\hline \multirow{4}{*}{$\begin{array}{l}\text { Intention to Adopt } \\
\text { M-Blackboard (IA) }\end{array}$} & IA1 & I intend to use smart phone devices for educational purposes \\
\hline & IA2 & $\begin{array}{l}\text { I have the sufficient knowledge and skills to use smart phone devices for educational } \\
\text { purposes }\end{array}$ \\
\hline & IA3 & I will prefer blackboard mobile over other medium of learning \\
\hline & IA4 & I will recommend other colleagues to use mobile devices for education purposes \\
\hline
\end{tabular}


variables and prepare to test the hypotheses. Finally, a regression analysis was employed to find the degree to which the model can explain variations in m-blackboard adoption. Specifically, this study utilizes the linear regression are show in Table 2 statistical technique to test the hypotheses using standard regression (for direct effect) and hierarchical regression (for indirect effect or moderating) are show in Tables 3 and 4.

\section{Analysis, Results and Discussion}

\subsection{Demographic Information of the Sample}

Through this study, $83 \%$ of the respondents are less than 24 years old, and the majority of students are still in their first degree of studies. Most of the respondents (69\%) are males. It's notable that the majority of the sample is newly blackboard adopters, 91\% of respondents had fewer than two years of experience using web blackboard platforms. The data analysis showed that, possessions of Smartphones respondents were dominating the sample (95\%). However, only $19 \%$ were using mobile devices to access blackboard platforms using a web browser instead of a mobile application.

\subsection{Descriptive Statistics of the Variables}

The standard deviation values are ranged from 0.64 to 0.82 . This indicates that most of the data points tend to be close to the means. The respondents agreed on almost all the items in the statements. Performance expectancy had the highest score (3.63), followed by effort expectancy with 3.6 and previous experience with 3.57. Other variables' mean scores are ranged from 3.01 to 3.45 . Alpha values are ranged from 0.78 to 0.91 , as all

Table 2. Results of linear regression analysis

\begin{tabular}{|c|c|c|c|c|c|c|}
\hline \multirow{2}{*}{$\mathbf{H} \#$} & Independent Variables & \multicolumn{2}{|c|}{ Unstandardized Coefficients } & \multirow{2}{*}{ R } & \multirow{2}{*}{ R Square } & \multirow{2}{*}{ Sig. } \\
\cline { 3 - 6 } & & $B$ & Std. Error & & & \\
\hline H1 & Self-Management Learning & .544 & .058 & .542 & .294 & 0.000 \\
\hline H2 & Cost & .230 & .069 & .224 & .050 & 0.001 \\
\hline H3 & Social Influence & .596 & .059 & .572 & .327 & 0.000 \\
\hline H4 & Perceived Playfulness & .642 & .053 & .639 & .409 & 0.000 \\
\hline H7 & Previous Experience & .754 & .048 & .736 & .541 & 0.000 \\
\hline
\end{tabular}

Significance levels are ${ }^{* * *} \mathrm{p}<.001,{ }^{* *} \mathrm{p}<.01,{ }^{\star} \mathrm{p}<.05$

Table 3. Results of hierarchical regression analysis

\begin{tabular}{|c|c|c|c|c|}
\hline \multirow[b]{2}{*}{$\begin{array}{c}\text { Independent } \\
\text { variable }\end{array}$} & \multicolumn{2}{|c|}{ Model H6a } & \multicolumn{2}{|c|}{ Model H6b } \\
\hline & $B$ & $S E B$ & $B$ & SE B \\
\hline $\begin{array}{l}\text { Performance } \\
\text { Expectancy }\end{array}$ & $0.65^{\star * *}$ & 0.051 & $0.261^{\star * *}$ & 0.067 \\
\hline Previous Experience & & & $0.556^{\star * *}$ & 0.067 \\
\hline $\begin{array}{l}\text { Interaction between } \\
\text { Performance } \\
\text { Expectancy X } \\
\text { Previous Experience }\end{array}$ & & & -0.003 & 0.038 \\
\hline $\mathbf{R 2}$ & \multicolumn{2}{|c|}{0.436} & \multicolumn{2}{|c|}{0.575} \\
\hline $\mathbf{F}$ & \multicolumn{2}{|c|}{$162.499^{\star * *}$} & \multicolumn{2}{|c|}{$93.944^{\star \star \star}$} \\
\hline
\end{tabular}

Significance levels are ${ }^{\star * \star} \mathrm{p}<.001,{ }^{\star *} \mathrm{p}<.01,{ }^{\star} \mathrm{p}<.05$
Table 4. Results of hierarchical regression analysis

\begin{tabular}{|c|c|c|c|c|}
\hline & \multicolumn{2}{|c|}{ Model H6a } & \multicolumn{2}{|c|}{ Model H6b } \\
\hline $\begin{array}{c}\text { Independent } \\
\text { variable }\end{array}$ & $B$ & SE B & $B$ & SE B \\
\hline Effort Expectancy & $.659^{* * *}$ & 0.050 & $0.242^{\star \star *}$ & .069 \\
\hline Previous Experience & & & $0.529^{* *}$ & .072 \\
\hline $\begin{array}{l}\text { Interaction between } \\
\text { Effort Expectancy X } \\
\text { Previous Experience }\end{array}$ & & & $-.082^{\star}$ & .038 \\
\hline $\mathbf{R 2}$ & \multicolumn{2}{|c|}{0.456} & \multicolumn{2}{|c|}{0.580} \\
\hline $\mathbf{F}$ & \multicolumn{2}{|c|}{$176.168^{\star * *}$} & \multicolumn{2}{|c|}{$95.642^{* * *}$} \\
\hline
\end{tabular}

Significance levels are ${ }^{\star * *} \mathrm{p}<.001,{ }^{* *} \mathrm{p}<.01,{ }^{\star} \mathrm{p}<.05$ 
Alpha values are more than 0.7 , thus, all the variables are reliable. In terms of convergent validity, each set of items for each variable was in the acceptable range, except the set of items for facilitating conditions; these items were poorly correlated, ranging from $(0.385$ to 0.719$)$ with a poor inter-item correlation $(>0.48)$ between the items. Therefore, all sets were then submitted for hypotheses testing (except for facilitating conditions (i.e. Hypothesis 8 , which were removed).

\subsection{Pearson Correlation Testing}

The results show that all the independent variables were correlated positively (ranged from 0.224 to 0.736 ); and significantly (at the high level $(0.01)$ with the sole dependent variable. These reflecting that the modification in any independent variable would direct to update the dependent variable in the same direction. Thus, all the variables were deserved for regression analysis.

\subsection{Regression Analysis Testing}

Results of testing hypotheses 1, 2, 3, 4, and 7 are shown in. The expected moderating influence as hypothesized in $\mathrm{H} 5 \mathrm{a}, \mathrm{H} 5 \mathrm{~b}, \mathrm{H} 6 \mathrm{a}$, and H6b are shown in.

Depends on the regression testing in, the hypotheses with results of data analysis and interpretation are listed. Raise intention to Self-management of learning, social influence, perceived playfulness, and previous experience are significant factors (significant at $a<0.05$ ) to sake adopting $\mathrm{m}$-blackboard. Particularly, the influence from self-management of learning, social influence, perceived playfulness, and previous experience for defining user's intention to adopt $\mathrm{m}$-blackboard is positive $(\beta=0.544, \beta$ $=0.596, \beta=0.642,0.754)$ respectively, and the R-square for the models are indicating that $29.4 \%, 32.7 \%, 40.9 \%$, $54.1 \%$ of disparity in intention to adopt m-blackboard can be described by self-management of learning, social influence, perceived playfulness, and previous experience respectively. Therefore, the $\mathrm{H} 1, \mathrm{H} 3, \mathrm{H} 4$, and $\mathrm{H} 7$ are supported. Surprising, cost is a significant factor to affect users' intention to adopt m-blackboard, with positive effect $(\beta=0.230)$, which is opposite to the effect hypothesized. While, at best $5.0 \%$ of disparity in intention to accept $\mathrm{m}$-blackboard can be expounding by cost. $\mathrm{H} 2$ is rejected.

As shown in a statistical value of $\mathrm{F}=162$ is significant at $\alpha<0.05$, reflecting that the model requires further explanation. The dissimilarity of $43.6 \%$ in the intention to adopt the M-blackboard system can be justified by performance expectancy. Performance expectancy can extremely raise $(\beta=0.650)$ the intention to use and adopt the M-blackboard system. Therefore, H6a is supported. Previous experience fails to play a moderating effect. Therefore, H6b is rejected.

As shown in, a statistical value of $\mathrm{F}=176.168$ is significant at $\alpha<0.05$. Effort expectancy directly and strongly increases $(\beta=0.659)$ the intention to adopt the M-blackboard system. This is consistent with H7a. As expected, the moderating effect from the interaction is negative $(\beta=-0.082)$. Therefore, previous experience is a significant moderator that decreases effort expectancy. This signals that the better experienced a user is, the less the anticipated endeavor of using the M-blackboard system, and consequently, the favorable the intention to adopt the system.

According to the finding of regression analysis, the whole selected factors invariably impact the behavioral intention to adopt m-blackboard as expected significantly, with the exception of the cost factor. These results are illustrated in the developed theoretical model as shown in Figure 2.

\section{Conclusion}

This study presents a theoretical research model that reflects all predictive factors influencing adoption of m-blackboard in the Saudi Arabia, and integrates a case study performed at universities in Saudi Arabia. Different factors and models involving behavior, maturity, and technology acceptance were reviewed and investigated using various scales. Based on the responses, the Pearson correlation statistic of the variables shows that all selected factors are linked with the behavioral intention to adopt m-blackboard. All selected factors positively affect the behavioral intention to adopt m-blackboard as expected, except the cost factor. This might refer to other factors associated with the context. Therefore, further investigation needed to discover a reasonable relation. That is, next researchers are advised to discover what factors might reverse the expected effect of such factor. In terms of the benefits of m-blackboard adoption, the responses indicate significant positive benefits such as easier access to information, greater productivity, time and cost savings, and the fact that it is accessible 
anywhere and anytime. The last section of the survey addresses the challenges of m-blackboard adoption. The respondents indicated that the greatest challenge is the weakness of mobile network signals, followed by the small screens of mobile devices, cost of connecting mobile devices to the internet, and the time needed to download the m-blackboard application.

Researchers recommended that the universities in Saudi Arabia should move forward toward adopting the m-blackboard platform. Previous studies, interviews with experts, and questionnaire responses all make clear that the m-blackboard platform allows better interactions between students and staff, provides easier access to class material, saves time and effort, and contributes to the use of current technologies to support education in colleges and universities. Future research on this topic will be conducted by building an m-blackboard platform for the universities in Saudi Arabia; this platform should be developed, tested, evaluated, and then made available for all students and staff to use. Future researchers are advised to investigate other aspects rather than the users' perception of adoption (e.g., learning environment, teachers' scaffolding, etc.). In addition, all challenges faced during m-blackboard adoption must be investigated, and the reason behind it must be dug deeper. Recommendations to handle all of these challenges must also be provided along with considering what was stated by 8 that students' assessment of course aside from the instructors' interactivity are the best factors affecting perceived satisfaction with LMS among students in Saudi Arabia. The LMS used (Blackboard) is the weakest factor influencing students' experience with online learning. Future researchers are advised to study m-learning from cultural perspectives and institutional readiness as asserted. M-learning is promising field of research, as many issues are yet to be investigated. Future researchers should investigate different types of previous experience, i.e., not only mobile technology or mobile application experience but also m-learning, M-LMS, and internet experience. In addition, they should understand the type, capabilities, and characteristics of sample respondents.

\section{Acknowledgement}

Researchers heart-fully acknowledge the support of the students in University of Hai'l for sharing information to use in this study.

\section{References}

1. Alsenaidy A, Ahmad TA. A review of current state m-government in Saudi Arabia. Global Engineers and Technologists Review. 2012; 2(5):5-8.

2. Communications and Information Technology Commission (Saudi Arabia) [Internet]. [cited 2018 May 17]. Available from: https://en.wikipedia.org/wiki/ Communications_and_Information_Technology_ Commission_(Saudi_Arabia).

3. Wai ISH, Ng SSY, Chiu DK, Ho KK, Lo P. Exploring undergraduate students' usage pattern of mobile apps for education. Journal of Librarianship and Information Science. 2018; 50(1):34-47. https://doi. org/10.1177/0961000616662699

4. Jawad HHM, Hassan ZB. Applying UTAUT to evaluate the acceptance of mobile learning in higher education in Iraq. International Journal of Science and Research. 2015; 4(5):952-4.

5. Alhussain T. Measuring the impact of the blackboard system on blended learning students. International Journal of Advanced Computer Science and Applications. 2017; 8(3):297-301. https://doi.org/10.14569/IJACSA.2017.080341

6. Mtebe J. Learning management system success: Increasing learning management system usage in higher education in sub-Saharan Africa. International Journal of Education and Development using ICT. 2015; 11(2):51-64.

7. Kuciapski M. Students acceptance of m-learning for higher education-UTAUT model validation. EuroSymposium on Systems Analysis and Design; 2016. p. 155-66. https://doi. org/10.1007/978-3-319-46642-2_11

8. Abdel-Jaber H. Experimental analysis of students' satisfaction factors in e-learning environment: A case study on Saudi Arabian University. Journal of Information and Knowledge Management. 2017; 16(2). https://doi. org/10.1142/S0219649217500186

9. Alshammari SH, Ali MB, Rosli MS. The influences of technical support, self-efficacy and instructional design on the usage and acceptance of LMS: A comprehensive review. Turkish Online Journal of Educational Technology. 2016; 15(2):116-25. 
10. Baabdullah AM, Williams YKDMD. Evaluating the unified theory of acceptance and use of technology (UTAUT2) in the Saudi Arabian context. Nascent Connections; 2013. p. $1-8$.

11. Al-Hujran O, Al-Lozi E, Al-Debei MM. Get ready to mobile learning: examining factors affecting college students' behavioral intentions to use m-learning in Saudi Arabia. Jordan Journal of Business Administration. 2014; 10(1):111-28. https://doi.org/10.12816/0026186

12. Almasri AKM. New mobile learning process model for higher education students in Jordanian universities. International Journal of Information, Business and Management. 2018; 10(1):201-13.

13. Shin WS, Kang M. The use of a mobile learning management system at an online university and its effect on learning satisfaction and achievement. The International Review of Research in Open and Distributed Learning. 2015; 16(3):110-30. https://doi.org/10.19173/irrodl.v16i3.1984

14. Han I, Shin WS. The use of a mobile learning management system and academic achievement of online students. Computers and Education. 2016; 102:79-89. https://doi. org/10.1016/j.compedu.2016.07.003

15. Asiimwe E. MLCMS actual use, perceived use, and experiences of use. International Journal of Education and Development using ICT. 2015; 11(1):101-21.

16. Mayisela T. The potential use of mobile technology: Enhancing accessibility and communication in a blended learning course. South African Journal of Education. 2013; 33(1):629. https://doi.org/10.15700/saje.v33n1a629

17. Kaliisa R, Picard M. A systematic review on mobile learning in higher education: The African perspective. Turkish Online Journal of Educational Technology. 2017; 16(1):118.

18. Mtebe J, Raisamo R. Investigating students' behavioural intention to adopt and use mobile learning in higher education in East Africa. International Journal of Education and Development using ICT. 2014; 10(3):4-20.

19. Venkatesh V, Thong JY, Xu X. Consumer acceptance and use of information technology: Extending the unified theory of acceptance and use of technology. MIS Quarterly; 2012. p. 157-78. https://doi.org/10.2307/41410412

20. Venkatesh V, Morris MG, Davis GB, Davis FD. User acceptance of information technology: Toward a unified view. MIS Quarterly; 2003. p. 425-78. https://doi. org/10.2307/30036540

21. Predictors of Mobile Learning Adoption [Internet]. [cited 2015 May]. Available from: https://www.researchgate.net/ publication/300715091_Predictors_of_Mobile_Learning_ Adoption.
22. Baabdullah AM, Alalwan AA, Al Qadi NS. Evaluating the current situation of mobile services (M-Services) in the Kingdom of Saudi Arabia. Emerging Markets from a Multidisciplinary Perspective; 2018. p. 149-60. https://doi. org/10.1007/978-3-319-75013-2_13

23. Masrek MN, Samadi I. Determinants of mobile learning adoption in higher education setting. Asian Journal of Scientific Research. 2017; 10(2):60-9. https://doi. org/10.3923/ajsr.2017.60.69

24. Yu CS. Factors affecting individuals to adopt mobile banking: Empirical evidence from the UTAUT model. Journal of Electronic Commerce Research. 2012; 13(2):104-21.

25. Ghalandari K. The effect of performance expectancy, effort expectancy, social influence and facilitating conditions on acceptance of e-banking services in Iran: The moderating role of age and gender. Middle-East Journal of Scientific Research. 2012; 12(6):801-7.

26. Yang H, Gui S. Factors influencing academic library users' intention to use mobile systems: A comparison of current users and potential adopters. 2014; 7(3):64-80.

27. Cigdem H, Ozturk M. Factors affecting students' behavioral intention to use LMS at a Turkish post-secondary vocational school. The International Review of Research in Open and Distributed Learning. 2016; 17(3):1-20. https:// doi.org/10.19173/irrodl.v17i3.2253

28. Motaghian H, Hassanzadeh A, Moghadam DK. Factors affecting university instructors' adoption of web-based learning systems: Case study of Iran. Computers and Education. 2013; 61:158-67. https://doi.org/10.1016/j. compedu.2012.09.016

29. Technology acceptance of smartphones as mobile learning tools: a contextual comparative study of engineering and education colleges [Internet]. [cited 2016]. Available from: https://ir.canterbury.ac.nz/handle/10092/13096.

30. Venkatesh V, Davis FD. A theoretical extension of the technology acceptance model: Four longitudinal field studies. Management Science. 2000; 46(2):186-204. https:// doi.org/10.1287/mnsc.46.2.186.11926

31. Malhotra Y, Galletta DF. Extending the technology acceptance model to account for social influence: Theoretical bases and empirical validation. Proceedings of the 32nd Annual Hawaii International Conference on Systems Sciences. 1999; 1:14.

32. Iqbal S, Qureshi IA. M-learning adoption: A perspective from a developing country. The International Review of Research in Open and Distributed Learning. 2012; 13(3):147-64.

33. Factors influencing students' acceptance of m-learning: an investigation in higher education [Internet]. [cited 2013]. Available from: http://www.irrodl.org/index.php/irrodl/ article/view/1631. 
34. Al Tabib S, Daud S, Ayub A, Mahmud R, Qoussini A. A proposed utilization model for mobile learning in sultan Qaboos University. Australian Journal of Basic and Applied Sciences. 2016; 10(13):55-62.

35. Uğur NG, Koç T, Koç M. An analysis of mobile learning acceptance by college students. Journal of Educational and Instructional Studies in the World. 2016; 6(2):1-11.

36. Shorfuzzaman M, Alhussein R. Modeling learners' readiness to adopt mobile learning: A perspective from a GCC higher education institution. Mobile Information Systems; 2016. p. 1-10. https://doi.org/10.1155/2016/6982824

37. Almasri AKM. Readiness and mobile learning process for higher education students in Jordanian Universities. ZENITH International Journal of Multidisciplinary Research. 2015; 5(1):85-96.

38. Alharbi S, Drew S. Using the technology acceptance model in understanding academics' behavioural intention to use learning management systems. International Journal of Advanced Computer Science and Applications. 2014; 5(1):143-55.https://doi.org/10.14569/IJACSA.2014.050120

39. Aharony N. Mobile libraries: librarians' and students' perspectives. College and Research Libraries. 2014; 75(2):202-17. https://doi.org/10.5860/crl12-415

40. Mac Callum K, Jeffrey L. The influence of students' ICT skills and their adoption of mobile learning. Australasian Journal of Educational Technology. 2013; 29(3):303-14. https://doi.org/10.14742/ajet.298

41. Park SY, Nam MW, Cha SB. University students' behavioral intention to use mobile learning: Evaluating the Technology Acceptance Model. British Journal of Educational
Technology. 2012; 43(4):592-605. https://doi.org/10.1111/ j.1467-8535.2011.01229.x

42. Liu Y, Han S, Li H. Understanding the factors driving m-learning adoption: A literature review. Campus-Wide Information Systems. 2010; 27(4):210-26. https://doi. org/10.1108/10650741011073761

43. Hadi FZ, Kishik AA. Acceptance of mobile learning among university students in Malaysia. Journal of Computing and Organisational Dynamics. 2014; 1(1):1-14.

44. Alam S. Critical success factors of mobile commerce usage in higher learning institution in Malaysia. Australian Journal of Basic and Applied Sciences. 2011; 5(12):241623.

45. Chang SE, Pan YHV. Exploring factors influencing mobile users' intention to adopt multimedia messaging service. Behaviour and Information Technology. 2011; 30(5):65972. https://doi.org/10.1080/01449290903377095

46. Alsmadi D, Chen J, Prybutok V, Gadgil G. E-learning in Jordanian higher education: Cultural perspectives and institutional readiness. Journal of Information and Knowledge Management. 2017; 16(4). https://doi. org/10.1142/S0219649217500356

47. Momani FMSM, Abualkishik AM. Factors influencing students' intention to adopt mobile blackboard. International Journal of Science and Research. 2014; 3(5):29-32.

48. Shahroury FR. A framework for mobile learning adoption. Indian Journal of Science and Technology. 2016; 9(48):1-6. https://doi.org/10.17485/ijst/2016/v9i48/109306 